\title{
Correlation of the location of superficial Barrett's esophageal adenocarcinoma (s-BEA) with the direction of gastroesophageal reflux
}

Authors

Institutions
Masami Omae'1, Junko Fujisaki', Tomoki Shimizu', Yusuke Horiuchi', Akiyoshi Ishiyama', Toshiyuki Yoshio', Toshiaki Hirasawa ${ }^{1}$, Yorimasa Yamamoto ${ }^{1}$, Tomohiro Tsuchida ${ }^{1}$, Masahiro Igarashi ${ }^{1}$, Yasuyuki Seto ${ }^{2}$

${ }^{1}$ Department of Gastroenterology, Cancer Institute Hospital, Japanese Foundation for Cancer Research, Tokyo, Japan ${ }^{2}$ Department of Gastrointestinal Surgery, The University of Tokyo, Tokyo, Japan submitted

16. November 2015 accepted after revision 18. January 2016

\section{Bibliography}

DOI http://dx.doi.org/

10.1055/s-0042-101757

Published online: 8.4.2016

Endoscopy International Open

2016; 04: E515-E520

(c) Georg Thieme Verlag KG

Stuttgart · New York

E-ISSN 2196-9736

\section{Corresponding author}

Masami Omae, MD

Department of

Gastroenterology

Cancer Institute Hospital

Japanese Foundation for Cancer

Research

3-81-6 Ariake

Koto-ku

Tokyo 135-8550

Japan

Fax: +81-3-35200141

masami.nego@jfcr.or.jp
Background: Superficial Barrett's esophageal adenocarcinoma (s-BEA) in Barrett's esophagus frequently occurs in the right wall of the esophagus. Our aim was to examine the correlation between the location of s-BEA and the direction of acid and non-acid reflux in patients with Barrett's esophagus.

Patients and methods: We performed 24-h pH monitoring in $33 \mathrm{~s}$-BEA patients using a pH catheter with eight sensors. One sensor was located at the 6 o'clock position in the lower esophagus and sensors 1-8 were arranged counterclockwise at the same level. The catheter was positioned at the same level as the s-BEA. We measured the maximal total duration of acid (MTD-A) and nonacid (MTD-NA) reflux. When the direction of

\section{Introduction \\ $\nabla$}

Superficial Barrett's esophageal adenocarcinoma (s-BEA) in Barrett's esophagus is frequently found in the right wall of the esophagus [1-4]. Pech et al. showed that more than half of s-BEAs were located at the 0-3 o'clock position in the distal esophagus [1]. Kariyawasam et al. also reported that, in Barrett's maximal segments of $5 \mathrm{~cm}$ or less, around half of all high grade dysplasias and early adenocarcinomas were located at the 2-5 o'clock position [2]. There is also a report indicating that the directional distribution of s-BEA is not influenced by the distance of the lesion from the gastroesophageal junction (GEJ) [3]. Overall, the available evidence indicates the potential importance of surveillance in these quadrants for early detection of s-BEA in patients with Barrett's esophagus.

On the other hand, it has been reported that esophageal mucosal breaks also mainly occur in the right anterior wall of the distal esophagus [4-6]. Edebo et al. have reported that mucosal breaks in patients with grade A or B esophagitis occurred most frequently in the right wall of the
MTD-A and MTD-NA coincided with the location of the s-BEA, the case was defined as coincidental and we calculated the rate of coincidence, and the probability of the rate of coincidence was estimated with $95 \%$ confidence intervals ( $95 \% \mathrm{CI}$ ).

Results: Among the 33 cases of s-BEA examined, the rate of coincidence of both MTD-A and MTDNA was $24 / 33(72.7 \%)$ ( $95 \%$ CI $0.54-0.87)$. The rate of coincidence of either MTD-A or MTD-NA was 30/33 (90.9\%) (95\%CI 0.76-0.98).

Conclusions: Our study revealed that the location of s-BEA mostly corresponds to the direction of MTD-A or MTD-NA. Accurate observation of the distribution of acid or non-acid reflux by $\mathrm{pH}$ monitoring would aid early detection of s-BEA by endoscopy.

distal esophagus [5]. Tongue-like short-segment Barrett's esophagus (SSBE) was more frequent in the right anterior wall (in the 0-2 o'clock position) than at other locations [4,7]. Using a pH catheter with eight sensors, Ohara et al. reported that patients with non-erosive reflux disease (NERD) and reflux esophagitis had radial asymmetric acid exposure that was predominant on the right wall of the distal esophagus [8]. So far, however, no published reports have examined the correlation between the location of s-BEA and the direction of acid or non-acid reflux individually. In the present study, we investigated this correlation in individual patients with Barrett's esophagus, hypothesizing that identification of the direction of acid or non-acid reflux in patients with Barrett's esophagus might be useful for early detection of s-BEA.

\section{Preliminary study \\ $\nabla$}

In a preliminary study, we performed 24-h pH monitoring in five healthy subjects, one patient with NERD, and two patients with s-BEA who 

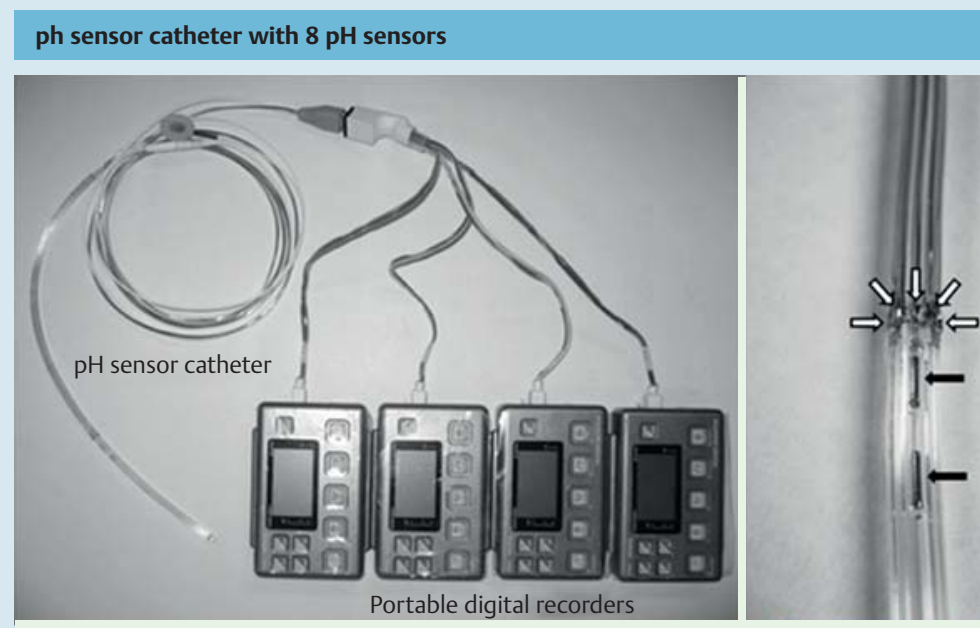

Preliminary study

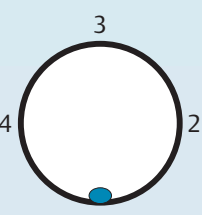

1

Main study

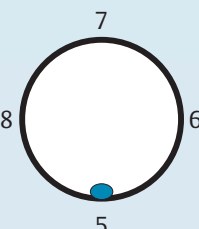

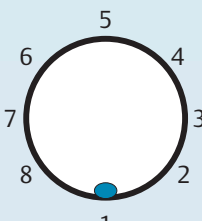

Cross section of the devices

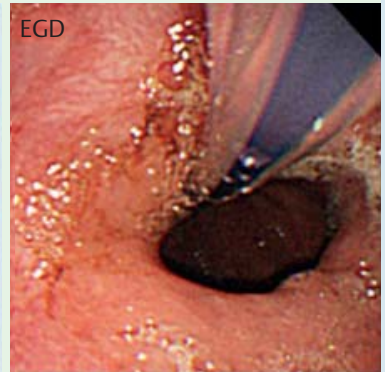

Fig. 1 The catheter used in our preliminary study had four sensors arrayed circumferentially at each of two levels. In our main study, the $\mathrm{pH}$ catheter had eight sensors (white arrows) arrayed circumferentially at the same level as the catheter. This catheter had a blue line on channel 1 located at the 6 o'clock position, and the eight sensors were arranged counterclockwise from that position (from Ref. [8]).

Table 1 Percentage total time when $\mathrm{pH}$ was $<4.0$ at every sensor in the preliminary study.

\begin{tabular}{|c|c|c|c|c|c|c|c|c|c|}
\hline & \multirow[t]{2}{*}{ Case } & \multicolumn{8}{|c|}{ Sensor } \\
\hline & & 1 & 2 & 3 & 4 & 5 & 6 & 7 & 8 \\
\hline \multirow[t]{5}{*}{ Healthy subjects } & 1 & 0.2 & 0.2 & 0.3 & $2.1^{*}$ & 0.1 & 0.1 & 0.3 & 0.3 \\
\hline & 2 & 0.5 & 0.5 & 0.6 & 0.5 & $0.7^{*}$ & 0.6 & 0.5 & 0.5 \\
\hline & 3 & 0.3 & 0.5 & 0.3 & 0.4 & 0.3 & 0.5 & $1.4^{*}$ & 0.6 \\
\hline & 4 & 2.1 & 0.4 & $2.5^{*}$ & 2.3 & 2.2 & 2.2 & 1.7 & 2.0 \\
\hline & 5 & 0.8 & $1.3^{*}$ & 0.7 & 0.6 & 0.3 & 0.4 & 0.4 & 0.3 \\
\hline NERD & 6 & 2.5 & $11.3^{\dagger}$ & $9.4^{\dagger}$ & 1.9 & 0.2 & 5.9 & 1.5 & 2.0 \\
\hline \multirow[t]{2}{*}{$s-B E A$} & 7 & 2.6 & $7.7^{\dagger}$ & $7.9^{\dagger}$ & 2.8 & 0.5 & 7.2 & 2.1 & 1.9 \\
\hline & 8 & 3.9 & 3.5 & $8.6^{\dagger}$ & 4.8 & 3.2 & $7.3^{\dagger}$ & 7.1 & 6.7 \\
\hline
\end{tabular}

NERD, non-erosive reflux disease; s-BEA, superficial Barrett's esophageal adenocarcinoma. Sensors 2, 3, 6, and 7 were located on the right anterior side. One NERD and two s-BEA patients had acid exposure predominantly on the right side. In contrast, in healthy subjects, there were no radial variations in acid reflux.

were not receiving proton pump inhibitors (PPIs). The two s-BEA lesions were located at the 2 o'clock position. We defined acid reflux as $\mathrm{pH}<4.0$ and non-acid reflux as $\mathrm{pH}>8.0$. The catheter we employed (SME Medizintechnik GmbH, Germany) has four $\mathrm{pH}$ sensors arranged circumferentially at two different levels. This catheter has a blue line on $\mathrm{pH}$ sensors 1 (lower channel) and 5 (upper channel) located at the 6 o'clock position in the lower esophagus ( Fig. 1). Sensors $1-4$ and $5-8$ are arranged counterclockwise at each level, and the upper channel is $5 \mathrm{~cm}$ distant from the lower channel ( $\bullet$ Fig. 1). The catheter was inserted transnasally into the esophagus after taking calibrations at $\mathrm{pH}$ 4.0 and 7.0, based on the manufacturer's instructions, and the lower $\mathrm{pH}$ channel of the catheter was positioned $2 \mathrm{~cm}$ above the squamo-columnar junction (SCJ), close to the usual site of mucosal breaks in patients with low grade esophagitis and s-BEA in patients with SSBE. pH data from the eight sensors can be recorded simultaneously by connecting the catheter to four portable digital recorders (Pocket Monitor GMMS-200pH; Star Medical).
This preliminary examination was performed during daily activity, and $\mathrm{pH}$ monitoring was done on a normal diet. The possibility of horizontal rotation and vertical movement during $\mathrm{pH}$ monitoring was examined by endoscopy. However, no horizontal rotation or vertical movement was observed when individuals were standing, sitting or supine, or when head and swallowing movements were performed, and we excluded any results for which the data indicated that the catheter had fallen into the stomach. We measured the total percentage period when $\mathrm{pH}$ was $<4.0$ as an indicator of acid reflux. Channels 2, 3, 6, and 7 were located on the right anterior side. The ${ }^{\dagger}$ numbers in 0 Table 1 indicate the total percentage period when $\mathrm{pH}$ was $<4.0$. This percentage exceeded $4 \%$, and was highest and second highest in NERD and s-BEA patients, respectively. On the other hand, the *numbers show the distribution of high acid readings in each of the healthy subjects. These results indicated that acid exposure was located predominantly on the right side in NERD and s-BEA patients, whereas in healthy subjects there was no radial variation of acid reflux $(\bullet$ Table 1$)$. 

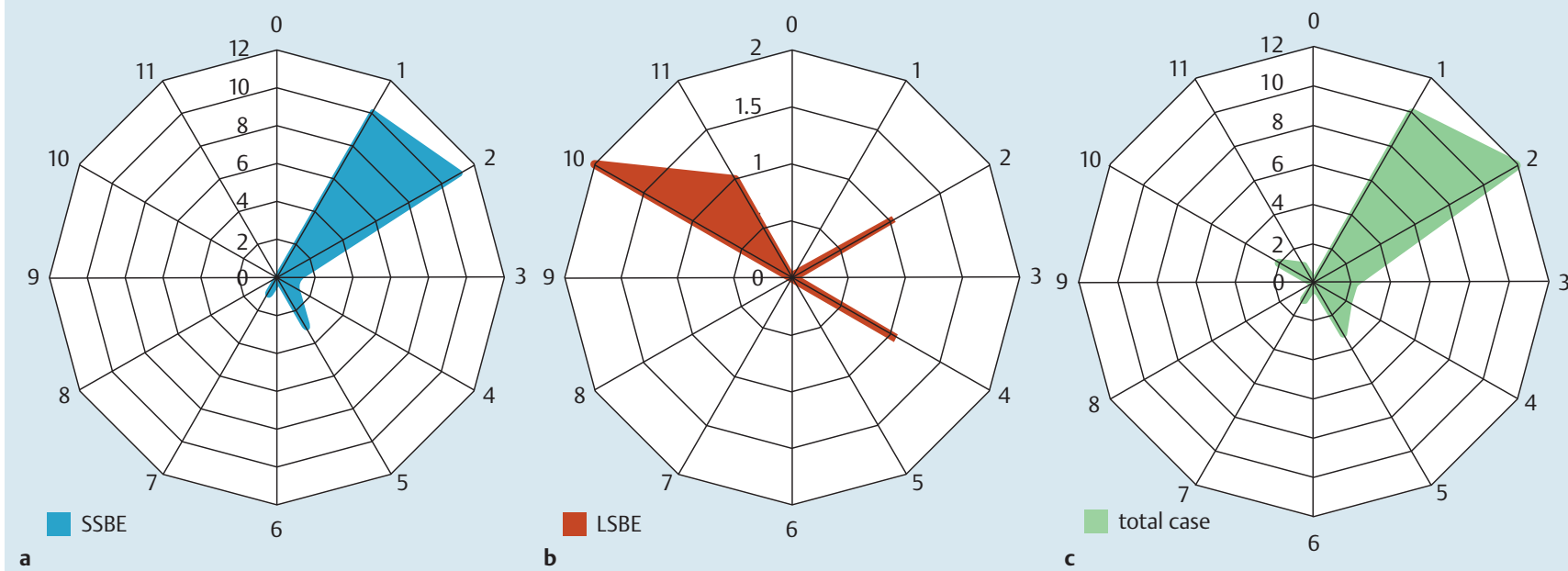

Fig.2 Distribution of the direction of s-BEA in (a) SSBE, (b) LSBE, and (c) all cases of Barrett's esophagus.

\section{Patients and methods \\ $\nabla$}

For this study, we retrospectively enrolled 37 s-BEA patients with solitary lesions who were treated with endoscopic submucosal dissection (ESD) or surgery between 2011 and 2014 at our hospital. However, the digital recorder failed in three patients and the catheter fell into the stomach in one patient, so the results of $\mathrm{pH}$ monitoring in these four patients were finally excluded, leaving $33 \mathrm{~s}-\mathrm{BEA}$ patients as the study subjects in whom all 33 lesions occupied no less than a third of the esophageal circumference. We histopathologically confirmed the diagnosis of s-BEA in all cases according to the Japanese classification of esophageal cancer [9]. The clinical characteristics of the patients are summarized in - Table2. Four of the patients (12.1\%) were women, and the mean patient age was 63.4 years (range $46-81$ years). Twentyeight patients (84.8\%) had SSBE and the remaining five patients (15.2\%) had long-segment Barrett's esophagus (LSBE). The depth of invasion in 18 of the s-BEA cases (54.5\%) was the mucosa, whereas in the remaining 15 cases (45.5\%) it was the submucosa. In SSBE cases, 23 lesions were distributed at the $0-3$ o'clock position, four at the 3-6 o'clock position, and one at the 6-9 o'clock position ( $\bullet$ Fig. 2a). On the other hand, among the LSBE cases, one lesion was distributed at the $0-3$ o'clock position, one at the 3-6 o'clock position, and three at the 9-0 o'clock position ( $\bullet$ Fig. 2b). Among the $33 \mathrm{~s}$-BEA lesions, 24 were distributed at $0-3$ o'clock, five at 3-6 o'clock, one at 6-9 o'clock, and three at $9-0$ o'clock ( $\odot$ Fig. 2c).

We performed 24-h pH monitoring before treatment of s-BEA by ESD or surgery. In this study, all of the patients had inevitably taken PPIs because some had suffered prolonged ESD beforehand. We defined acid reflux as $\mathrm{pH}<4.0$ and non-acid reflux as $\mathrm{pH}>8.0$, even under PPI medication. The catheter we employed has eight $\mathrm{pH}$ sensors circumferentially arrayed at the same level as that in the device developed by Shimane Medical University and Star

Table 2 Clinical characteristics of the study patients.

\begin{tabular}{|ll|}
\hline Gender, male/female (\%) & $29 / 4(87.9 / 12.1)$ \\
\hline Mean age, years (range) & $63.4(46-81)$ \\
\hline Barrett's esophagus, SSBE/LSBE (\%) & $28 / 5(84.8 / 15.2)$ \\
\hline Tumor invasion depth, mucosal/submucosal (\%) & $18 / 15(54.5 / 45.5)$ \\
\hline
\end{tabular}

SSBE, short-segment Barrett's esophagus; LSBE, long-segment Barrett's esophagus.
Medical (Tokyo, Japan) (8-channel pH catheter SA800). This catheter also had a blue line on sensor 1 located at the 6 o'clock position in the lower esophagus, and sensors $1-8$ were arranged in turn in a counterclockwise direction ( $\bullet$ Fig. 1 ). It was inserted transnasally into the esophagus and positioned at the same level as the neoplasia in all $33 \mathrm{~s}$-BEA patients. Catheter insertion was performed in the afternoon, and in the evening the patients took liquid food. On the following day, ESD or surgery was performed. Channel 1 of the catheter was positioned at 6 o'clock in the lower esophagus, and this positioning was confirmed by endoscopic observation of the blue marker line ( $\boldsymbol{0}$ Fig. $\mathbf{1}$ ). The conditions employed, such as daily activities and diet, were the same as those for our preliminary test.

We measured the maximal total duration of acid and non-acid reflux (maximal total duration of acid reflux [MTD-A] or maximal total duration of non-acid reflux [MTD-NA]) for 24 hours in all 33 s-BEA patients. We then divided the esophageal locations of the catheter sensors into eight parts circumferentially. When the direction of MTD-A and MTD-NA coincided with the location of the $\mathrm{s}-\mathrm{BEA}$, the case was defined as a coincidental case and we calculated the rate of coincidence and the probability of the rate of coincidence was estimated with $95 \%$ confidence intervals (95\% $\mathrm{CI}$ ). An example of such a case is shown in $\bullet$ Fig. 3. This is a typical s-BEA case located at the $0-3$ o'clock position in the distal esophagus. In this case, the direction of MTD-A and MTD-NA was located at sensor 4 in the $0-3$ o'clock position.

\section{Ethics}

The study was conducted in accordance with the Declaration of Helsinki, and the study protocol was approved by the medical ethics committee of our hospital. The risks and benefits of this examination were explained beforehand, and written informed consent was obtained from all 33 patients.

\section{Results}

$\nabla$

In 28 patients with SSBE, including four s-BEA patients without acid reflux, the location of $19 \mathrm{~s}$-BEAs (67.9\%) corresponded to the direction of MTD-A (95\% $0.48-0.84)$. Among the coincidental cases, 16 of the s-BEAs ( $84.2 \%)$ were located at the $0-3$ o'clock position, two $(10.5 \%)$ at $3-6$ o'clock, and one $(5.3 \%)$ at 

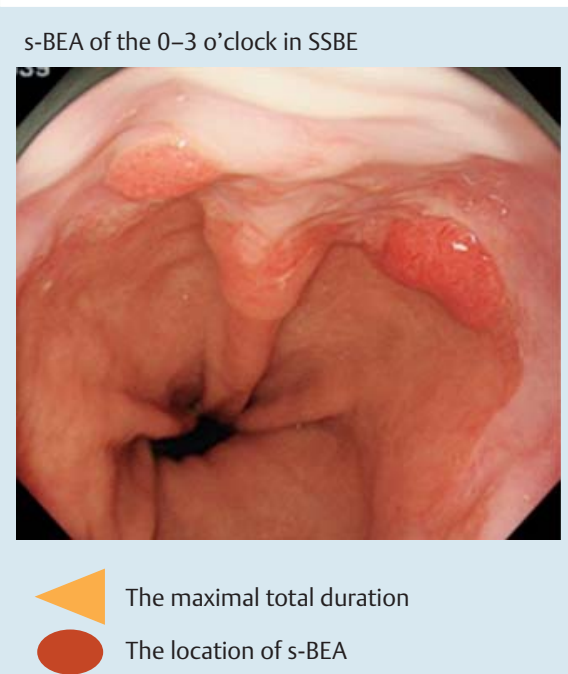

The maximal total duration

The location of s-BEA

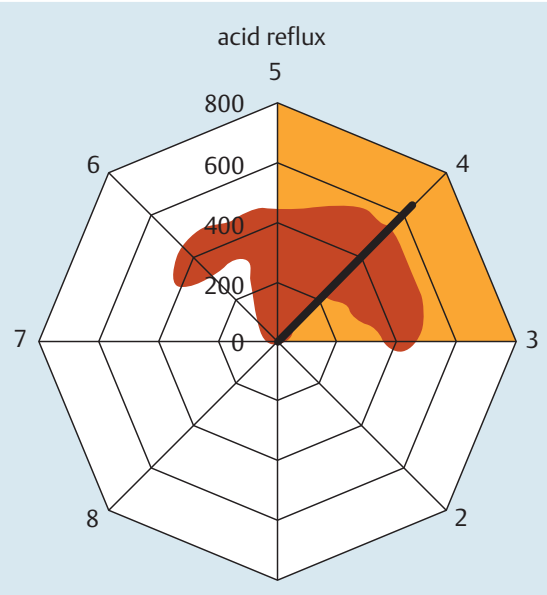

1

4 channel 0-3 o'clock

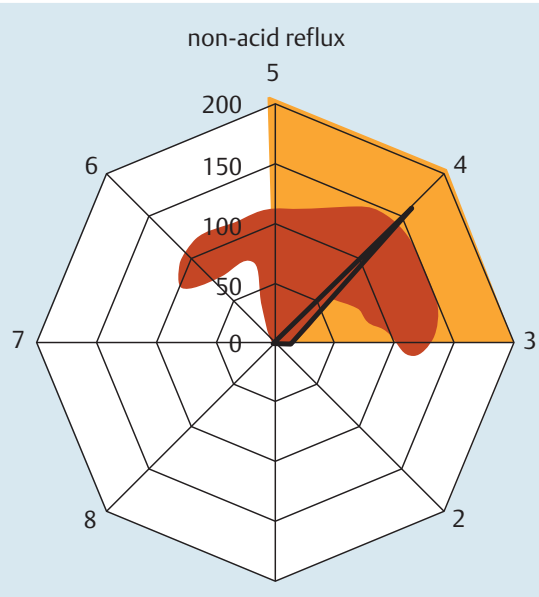

1

4 channel

0-3 o'clock

Fig. 3 A s-BEA case located at the $0-3$ o'clock position in the lower esophagus. MTD-A and MTD-NA were detected by sensor 4 in the $0-3$ o'clock position, and therefore this case was coincidental with acid and non-acid reflux.
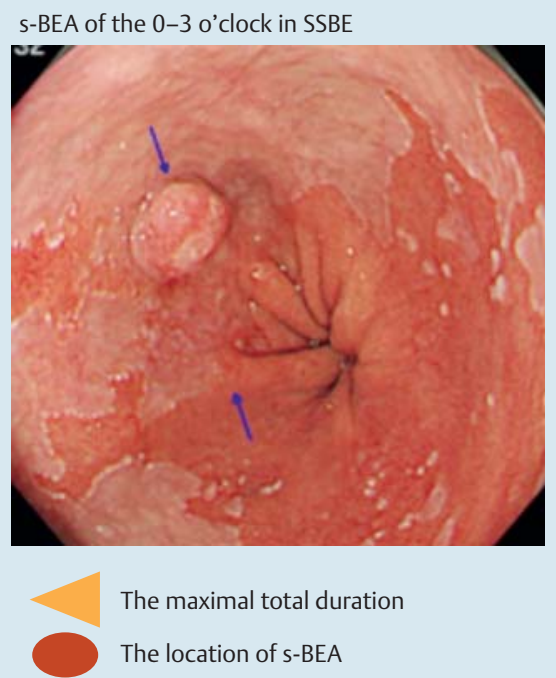

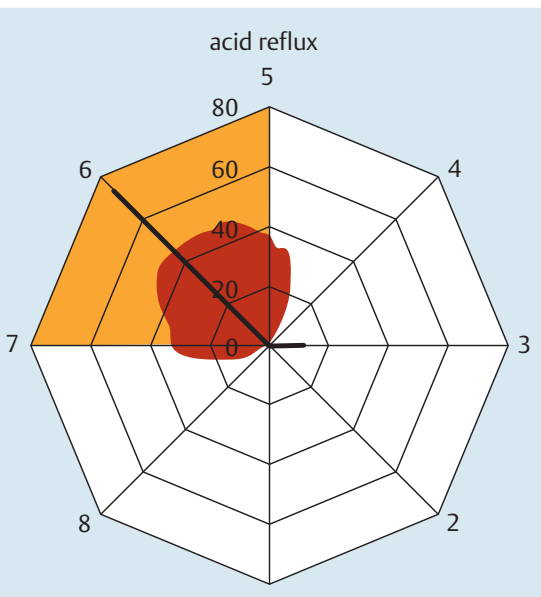

1

5-7 channel, 9-0 o'clock

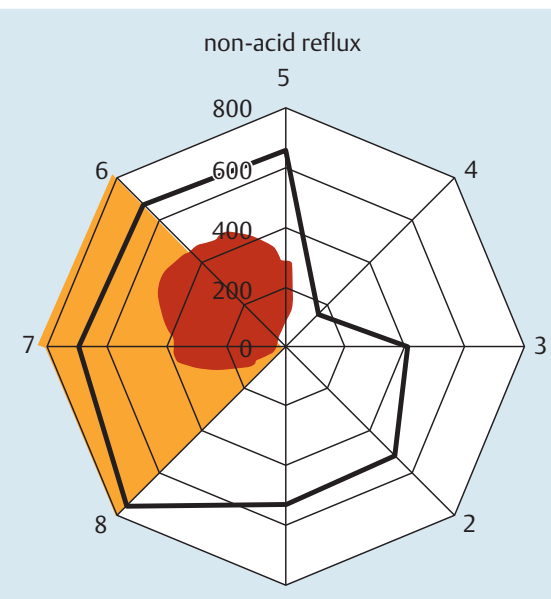

6-8 channel, 8-10 o'clock

Fig. 4 A s-BEA case located at the 9-10 o'clock position in BE. MTD-A was detected by sensors $5-7$ in the $9-0$ o'clock position, and MTD-NA was detected by sensors $6-8$ in the $8-10$ o'clock position. Therefore this case was coincidental with both acid and non-acid reflux.

6-9 o'clock in the lower esophagus. In all five patients with LSBE, the location of the s-BEAs (100.0\%) corresponded to the direction of MDT-A (95\%CI 0.48-1.00). Among these five coincidental cases, one s-BEA (20.0\%) was located at the $0-3$ o'clock position, one $(20.0 \%)$ at the $3-6$ o'clock position, and the others $(60.0 \%)$ at the $9-0$ o'clock position in the lower esophagus. Among the $33 \mathrm{~s}-$ BEA cases, the MTD-A or MTD-NA coincided in $24(72.7 \%)(95 \% \mathrm{CI}$ $0.54-0.87)$.

On the other hand, among the 28 SSBE patients with non-acid reflux, including 3 s-BEA patients without non-acid reflux, the location of 20 of the s-BEAs (71.4\%) corresponded to the direction of MTD-NA (95\%CI 0.51-0.87). Among these 20 coincidental cases, 17 of the s-BEAs (89.5\%) were located at $0-3$ o'clock, two (10.0\%) were located at 3-6 o'clock, and one (5.0\%) was located at 6-9 o'clock in the lower esophagus. Among the five non-acid reflux patients with LSBE, four of the s-BEAs (80.0\%) corresponded to the direction of MTD-NA (95\%CI 0.28-0.99); three of these $(60.0 \%)$ were located at $9-0$ o'clock, and the remaining one $(20.0 \%)$ was located at 3-6 o'clock. Among the 33 non-acid reflux patients with s-BEAs, the MTD-NA coincided in 24 (72.7\%) (95\%CI 0.54-0.86). Overall, the rate of coincidence of either MTD-A or MTD-NA was 30/33 (90.9\%) (95\%CI 0.76-0.98) ( $\bullet$ Table 3).

\section{Case presentation}

$\nabla$

- Fig. 4 illustrates a case of s-BEA at the 9-10 o'clock position in Barrett's esophagus. MTD-A was detected by sensors 5-7, in the 9-0 o'clock position, and MTD-NA was detected at sensors 6-8, in the $8-10$ o'clock position. Therefore, in this case, the positions of acid and non-acid reflux coincided. 
Table 3 Rates of coincidence between s-BEA location and the direction of MTD-A and MTD-NA in all 33 s-BEA patients.

\begin{tabular}{|c|c|c|c|c|c|}
\hline Fluid reflux & $\begin{array}{l}\text { Number of Barrett's } \\
\text { esophagus cases }\end{array}$ & $\begin{array}{l}\text { Number of coincidental } \\
\text { cases }\end{array}$ & $\begin{array}{l}\text { Coincidence rate (\%) } \\
95 \% \mathrm{CI}\end{array}$ & $\begin{array}{l}\text { Coincidence rate (\%) } \\
95 \% \mathrm{Cl}\end{array}$ & $\begin{array}{l}\text { Total coincidence rate } \\
\text { (\%) } \\
95 \% \mathrm{Cl}\end{array}$ \\
\hline Acid & $\begin{array}{l}28 \\
\text { SSBE } \\
5 \\
\text { LSBE }\end{array}$ & 19 & $\begin{array}{l}19 / 28(67.9) \\
0.48-0.84 \\
5 / 5(100.0) \\
0.48-1.00\end{array}$ & $\begin{array}{l}24 / 33(72.7) \\
0.54-0.87\end{array}$ & $\begin{array}{l}30 / 33(90.9) \\
0.76-0.98\end{array}$ \\
\hline Non-acid & $\begin{array}{l}28 \\
\text { SSBE } \\
5 \\
\text { LSBE }\end{array}$ & 20 & $\begin{array}{l}20 / 28(71.4) \\
0.51-0.87 \\
4 / 5(80.0) \\
0.28-0.99\end{array}$ & $\begin{array}{l}24 / 33(72.7) \\
0.54-0.87\end{array}$ & \\
\hline
\end{tabular}

MTD-A, maximal total duration of acid; MTD-NA, maximal total duration of non-acid; SSBE, short-segment Barrett's esophagus; LSBE, long-segment Barrett's esophagus.

\section{Discussion}

Mucosal breaks in patients with grade A or B esophagitis and tongue-like SSBE occur most frequently in the right wall of the distal esophagus [4-7]. s-BEA is frequently found in the right wall of the esophagus [1 -4]. However, no published studies have investigated the reason for this.

In the SSBE patients we studied, the $0-3$ o'clock position in the esophagus accounted for the majority of s-BEAs: 23 cases. On the other hand, in LSBE patients, the 9-0 o'clock position accounted for the majority of s-BEAs: three cases. The position of the latter three lesions coincided with the direction of MTD-A or MTD-NA. Among the 33 s-BEA patients as a whole, the direction of either MTD-A or MTD-NA coincided in 30 (90.9\%).

The present study investigated whether MTD-A or MTD-NA could be used as an indicator of the site of occurrence of s-BEA. No obvious indicators of the site of s-BEA occurrence have been reported so far, although a few studies have attempted to monitor esophageal acid exposure by $\mathrm{pH}$ detection in Barrett's esophagus. Fass et al. reported that patients with LSBE had significantly more frequent esophageal acid exposure than patients with SSBE. The duration of esophageal acid exposure seems to be an important factor determining the length of Barrett's esophagus [10]. Menges et al. suggested that there is a good correlation between the duration of esophageal exposure to acid and bile and the severity of pathological change in the esophagus [11]. However, no reports have attempted to define the duration of acid exposure as a risk factor for s-BEA. Virchow described the presence of leukocytes in tumors, and hypothesized that the origin of cancer lay at the site of chronic inflammation. It has been reported that chronic infections are associated with $15-20 \%$ of malignant tumors $[12,13]$. In BEA, esophagitis is caused by gastroesophageal reflux. Therefore, we considered that MTD-A and MTD-NA could be defined as indicators of s-BEA occurrence.

Recently, especially in Japan, endoscopic treatments, including ESD and endoscopic mucosal resection, have been shown to be safe, effective, and minimally invasive for s-BEA in patients with Barrett's esophagus [14-16]. In the present series, ESD was selected for tumors without any submucosal invasion, whereas surgery was indicated for tumors showing obvious submucosal invasion. Patients with high grade intraepithelial neoplasia and intramucosal cancer have been shown to have only a minimal risk of lymph node metastasis, and therefore endoscopic therapy is generally regarded as curative. When cancer invades the submucosal layer, the risk of lymph node positivity rises to $20 \%[17,18]$. Prevention of cancer death therefore requires early detection by endoscopy surveillance when the cancer is still curable at an early stage.

Although no prospective and randomized controlled study has clarified the efficacy of surveillance endoscopy for prevention of cancer-related death in patients with Barrett's esophagus, it is globally recommended by most gastroenterology societies [1921]. Retrospective series have lent support to the opinion that endoscopic biopsy surveillance of Barrett's esophagus facilitates detection of s-BEA at an early and curable stage, thereby potentially reducing mortality due to esophageal adenocarcinoma $[22,23]$. A recent randomized, crossover trial has shown that narrow-band imaging (NBI) targeted biopsies can detect intestinal metaplasia at a rate similar to high definition white-light endoscopy examination with the Seattle protocol, while requiring fewer biopsies. In addition, NBI targeted biopsies can detect more areas with dysplasia, and obviate the need for biopsies of those lesions showing regular surface patterns [24]. Therefore, if observation of the location and distribution of acid or non-acid reflux by $\mathrm{pH}$ monitoring could be combined with NBI target biopsy, detection and curability of s-BEA would be maximized.

There were some limitations to our study. First, almost all of the 33 s-BEA patients were taking PPIs during $\mathrm{pH}$ monitoring. In practice, however, we have found that, in patients not taking PPIs, ESD was prolonged and the esophagitis was worsened, making the borderline of s-BEA less clear. Our purpose in this study was to reveal the prevailing distribution of acid or nonacid reflux. The most essential point was to evaluate the direction of MTD-A or MTD-NA individually. Second, there was a problem with horizontal rotation and vertical movement. The possibility of this occurring during $\mathrm{pH}$ monitoring was examined by endoscopy, but none was observed during standing, sitting or remaining supine, or during head movements and swallowing. In addition, the digital recorder failed in three patients and the catheter fell into the stomach in one patient, so the results of $\mathrm{pH}$ monitoring for these four patients had to be excluded. Third, the numbers of patients examined were small, especially those with LSBE. In order to investigate the correlation between the direction of MTD-A and MTD-NA with the location of s-BEA, more patients with LSBE will need to be studied. Moreover, it will be necessary to verify prospectively whether endoscopic surveillance of the direction of acid and non-acid reflux, by performing $\mathrm{pH}$ monitoring of Barrett's esophagus with no neoplasia, would aid the early detection of s-BEA.

Here we found that the location of s-BEA mostly corresponded to the direction of MTD-A or MTD-NA. Currently, no method of endoscopic surveillance for Barrett's esophagus has been de- 
vised. However, our present experience shows that it is possible to predict the location of s-BEA using a $\mathrm{pH}$ catheter with eight sensors. Therefore, endoscopic observation of the prevailing distribution of acid or non-acid reflux by $\mathrm{pH}$ monitoring appears to have potential for early detection of s-BEA.

\section{Competing interests: None}

\section{References}

1 Pech O, Gossner L, Manner $H$ et al. Prospective evaluation of the macroscopic types and location of early Barrett's neoplasia in 380 lesions. Endoscopy 2007; 39: 588-593

2 Kariyawasam VC, Bourke MJ, Hourigan LF et al. Circumferential location predicts the risk of high-grade dysplasia and early adenocarcinoma in short-segment Barrett's esophagus. Gastrointest Endosc 2012; 75: 938-944

3 Cassani L, Sumner E, Slaughter JC et al. Directional distribution of neoplasia in Barrett's esophagus is not influenced by distance from the gastroesophageal junction. Gastrointest Endosc 2013; 77: 877-882

4 Kinoshita Y, Furuta K, Adachi K et al. Asymmetrical circumferential distribution of esophagogastric junctional lesions: anatomical and physiological considerations. J Gastroenterol 2009; 44: 812 -818

5 Edebo A, Vieth M, Tam $W$ et al. Circumferential and axial distribution of esophageal mucosal damage in reflux disease. Dis Esophagus 2007; 20: $232-238$

6 Katsube T, Adachi K, Furuta K et al. Difference in localization of esophageal mucosal breaks among grades of esophagitis. J Gastroenterol Hepatol 2006; 21: 1656-1659

7 Okita K, Amano Y, Takahashi Yet al. Barrett's esophagus in Japanese patients: its prevalence, form, and elongation. J Gastroenterol 2008; 43 : 928-934

8 Ohara S, Furuta K, Adachi K et al. Radially asymmetric gastroesophageal acid reflux in the distal esophagus: examinations with novel $\mathrm{pH}$ sensor catheter equipped with 8 pH sensors. J Gastroenterol 2012; 47: $1221-1227$

9 Japan Esophageal Society. Japanese classification of esophageal cancer. 10th: edn. Tokyo: Kanehara Shuppan; 2008

10 Fass R, Hell RW, Garewal HS et al. Correlation of oesophageal acid exposure with Barrett's oesophagus length. Gut 2001; 48: 310-313

11 Menges M, Muller M, Zeitz M. Increased acid and bile reflux in Barrett's esophagus compared to reflux esophagitis, and effect of proton pump inhibitor therapy. Am J Gastroenterol 2001; 96: 331-337
12 Kuper H, Adami HO, Trichopoulos D. Infections as a major preventable cause of human cancer. J Intern Med 2000; 248: 171-183

13 Parkin DM. The global health burden of infection-associated cancers in the year 2002. Int J Cancer 2006; 118: 3030-3044

14 Omae M, Fujisaki J, Horiuchi Yet al. Safety, efficacy, and long-term outcomes for endoscopic submucosal dissection of early esophagogastric junction cancer. Gastric Cancer 2013; 16: 147-154

15 Yamada M, Oda I, Nonaka S et al. Long-term outcome of endoscopic resection of superficial adenocarcinoma of the esophagogastric junction. Endoscopy 2013; 45: 992 - 996

16 Goda K, Singh R, Oda I et al. Current status of endoscopic diagnosis and treatment of superficial Barrett's adenocarcinoma in Asia-Pacific region. Dig Endosc 2013; 25: 02146-150

17 Stein HJ, Feith M, Bruecher BL et al. Early esophageal cancer: pattern of lymphatic spread and prognostic factors for long-term survival after surgical resection. Ann Surg 2005; 242: 566-573 ; discussion 573565

18 Buskens CJ, Westerterp M, Lagarde SM et al. Prediction of appropriateness of local endoscopic treatment for high-grade dysplasia and early adenocarcinoma by EUS and histopathologic features. Gastrointest Endosc 2004; 60: 703-710

19 Playford RJ. New British Society of Gastroenterology (BSG) guidelines for the diagnosis and management of Barrett's oesophagus. Gut 2006; 55: 442

20 Hirota WK, Zuckerman MJ, Adler DG et al. ASGE guideline: the role of endoscopy in the surveillance of premalignant conditions of the upper GI tract. Gastrointest Endosc 2006; 63: 570-580

21 Wang KK, Sampliner RE. Updated guidelines 2008 for the diagnosis, surveillance and therapy of Barrett's esophagus. Am J Gastroenterol 2008; 103: 788 - 797

22 van Sandick JW, van Lanschot JJ, Kuiken BW et al. Impact of endoscopic biopsy surveillance of Barrett's oesophagus on pathological stage and clinical outcome of Barrett's carcinoma. Gut 1998; 43: 216-222

23 Streitz JMJr, Andrews CWJr, Ellis FHJr. Endoscopic surveillance of Barrett's esophagus. Does it help? J Thorac Cardiovasc Surg 1993; 105: 383-387; discussion 387-388

24 Sharma P, Hawes RH, Bansal A et al. Standard endoscopy with random biopsies versus narrow band imaging targeted biopsies in Barrett's oesophagus: a prospective, international, randomised controlled trial. Gut 2013; 62: 15-21 